\title{
Morphological diversity and microevolutionary aspects of the lineage Cryptocandona vavrai Kaufmann, 1900 (Ostracoda, Candoninae)
}

\author{
S. Iepure ${ }^{1}$, T. Namiotko², D.L. Danielopol ${ }^{3 *}$ \\ ${ }^{1}$ Institute of Speleology “Emil Racoviță”, Romanian Academy, Clinicilor 5, RO - 400006 Cluj, Romania \\ 2 Department of Genetics, Institute of Biology, University of Gdańsk, Kładki 24, PL 80-822 Gdańsk, Poland \\ ${ }^{3}$ Commission of the Stratigraphical \& Palaeontological Research of Austria, Austrian Academy of Sciences, c/o Institute of Earth Sciences \\ (Geology \& Palaeontology), University of Graz, Heinrichstrasse 26, A-8010 Graz, Austria
}

Morphology of both the valves and limbs of several parthenogenetic populations of the widespread non-marine ostracod Cryptocandona vavrai Kaufmann (sensu lato) living in groundwater habitats of western (France) and south-eastern Europe (Romania) was examined for the extent of intra- and interpopulational variation. Geometric morphometrics and multivariate statistics were employed for the description of the valve morphological disparity whereas the discriminant analysis was performed for the comparative analysis of the limb chaetotaxy. The ranges of the most studied limb traits principally overlapped among the populations, however considerable differences in the carapace shape and size, reflecting microevolutionary changes at a macro-scale (inter-population) level, allowed distinguishing quantitatively some Romanian populations which deserve a separate specific status. Hence, a new species Cryptocandona racovitzai sp. nov. is described which differs from $C$. vavrai sensu stricto mainly in larger size, in more triangular valve shape as seen laterally and in less developed inner lamella of the valves. Finally, after examination of more material from Romanian groundwaters, we hypothesised the presence of more new species within the studied lineage and concluded that Cryptocandona vavrai sensu lato is a polymorphic lineage consisting of several geographically differentiated species rather than just only one widely dispersed species.

Keywords: groundwater, Recent Candoninae, comparative morphology, microevolution, taxonomy.

\section{Introduction}

Increasing number of comparative morphological studies of several ostracod (Crustacea: Ostracoda) taxa that inhabit surface and subsurface environments has demonstrated the high capacity of some phylogenetic lineages to evolve in time, leading to further speciation through vicariance (Rogulj et al. 1993, Baltanás et al. 2000, Namiotko et al. 2005a, Iepure et al. 2007). Much attention has been given to the exclusively subterranean dwelling ostracods, of which most are restricted to a specific geographic area and clearly display a high capacity of evolvability expressed by different patterns of morphological variation of the valves and/or limbs (Rogulj et al. 1993, Namiotko et al. 2005a, Iepure et al. 2007). Species that show a wide geographic distribution and a high capacity to colonise both surface and subsurface water habitats are known through local populations, often geo-

\footnotetext{
* Corresponding author: E-mail: dan.danielopol@oeaw.ac.at
}

graphically separated by gaps of tens to hundreds kilometres and are expected to show trends in morphological separation of their isolated population (Baltanás et al. 2000). The composition and size of the initial founder populations together with additional local ecological factors and the geographic isolation may play a significant role in an increase of morphological divergences that are known to occur between these populations (Iepure et al. 2007).

Here we further explore this topic using subterranean populations of a stygophilic ostracod species Cryptocandona vavrai Kaufmann, originally described from southern Switzerland by Kaufmann (1900a, 1990b) and considered now a distinct phylogenetic lineage within the genus Cryptocandona (Baltanás et al. 2000, Namiotko \& Danielopol 2002, Namiotko et al. 2005b). The species is represented by parthenogenetic populations (with rare occurrence of single males) broadly distributed in Europe except for the southern- and easternmost areas (Meisch 2000, Namiotko et al. 2005b), and 
although generally considered a crenobiontic stygophile, it has a wide range of tolerance to various environments, being reported from both epigean (e.g. lentic habitats of lakes, temporary water bodies) and groundwater habitats (e.g. hyporheal, deep groundwater in alluvial sediments) (Danielopol 1980, Baltanás et al. 2000, Meisch 2000, Namiotko et al. 2005b). Cryptocandona vavrai has been the subject of two recent contributions focused on the morphological disparity of both, carapace shapes and limb chaetotaxy (Baltanás et al. 2000, Namiotko et al. 2005b). The morphometric analysis performed on the carapace outlines of eight species of the genus (including C. vavrai) from distantly geographic areas in Europe and Japan allowed getting insights on the disparity pattern of the valve shapes evaluated in the context of geographical and ecological distribution of these species (Baltanás et al. 2000). The limb morphology comparison between females of $C$. vavrai from surface and subsurface waters revealed remarkable elongation of some apical claws and aesthetascs in the latter population (Namiotko et al. 2005b). Furthermore, comparative morphological descriptions of rare males showed that the major difference recorded was the underdevelopment of some of the terminal antennal claws in the male from the underground waters in Romania, indicating considerable intraspecific variation (Namiotko et al. 2005b).

In the present paper we continue the series of studies focused on the morphological diversity of Cryptocandona vavrai. We examined the morphological disparity of both valves and limbs in four geographically separated all-female populations of Cryptocandona vavrai from subsurface habitats in western and eastern Europe, two in France and two in Romania, respectively. In the first part of the present study the morphological diversity (disparity) of the valve shape was assessed based on morphometric analysis by Linhart's B-splines algorithm (Baltanás et al. 2003, Brauneis et al. 2006) and further by multivariate statistical analyses. The valve shape disparity was examined at two hierarchical levels: 1 ) as a phenotypic variety within a population that occur within one time slice, and 2) as a phenotypic variety originated through evolutionary change, i.e. morphological transformation over long periods of time when one compares populations or species that belong to an evolutionary lineage ( $c f$. Ciampaglio et al. 2001, Winther 2001). To supplement these data, comparative descriptions of the valve shapes of females collected from underground waters at two additional sites in Romania are also included in this paper. In the second part of the study the limb morphology of females from underground waters at the four sites was analysed by multivariate statistical methods in order to evaluate variability of the soft part morphology comparatively with the valve shape disparity, thus facilitating further extension of our knowledge of the variation patterns in this lineage and finally a taxonomic decision on the description of a new species.

The present contribution constitutes a part of an extensive revision of the taxonomy, ecology and biogeography of the group of species classified in the genus Cryptocandona, which can be split in several phylogenetic lineages (Baltanás et al. 2000, Namiotko \& Danielopol 2001, Namiotko et al. 2001, Namiotko \& Danielopol 2002, Namiotko et al. 2005a, 2005b).

\section{Material and methods}

\section{Sampling sites}

For our comparative approach, we investigated females identified initially as Cryptocandona vavrai sensu lato from four main collections made in different groundwater habitats of western and eastern Europe (Fig. 1). Two of the sites are located in eastern and southern France:

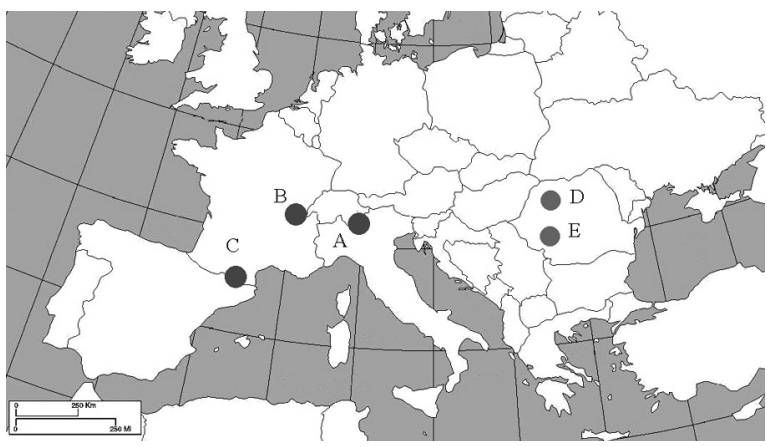

Fig. 1. The type locality of Cryptocandona vavrai and localities from which material was obtained for the present study: A Gentilino (locus typicus), B - Arcine, C - Alas, D - Bulz, Şuncuiuş and Sighiştel, E - Isverna.

- Arcine (AR), $25 \mathrm{~km}$ NW of Annecy, Haute-Savoie, Rhône Alpes (approx. geographic co-ordinates: 460ㅜ N, 5-54' E). The material was collected by P. Marmonier in August and September 1997 from a well accessing to an unconfined aquifer recharged by the Rhône River (for more details see description of the well F4 in Mallard et al. 1997 and Namiotko et al. 2005b).

- Alas (AL), 10 km SW of Saint-Girons, Ariège, Midi-Pyrénées (approx. geographic co-ordinates: 42057' $\left.\mathrm{N}, 1^{\circ} 03^{\prime} \mathrm{E}\right)$. The material was collected by R. Rouch on 4 of February 1986 from the hyporheal of the Lachein stream at 50-100 cm depth (more details in Rouch 1988). 
Two other samples were collected from wells that give direct access to the groundwater of the Crişul Repede River located in north-western Romania (Fig. 1):

- Bulz (BU) ca. $60 \mathrm{~km}$ ESE of Oradea, Bihor County (approx. geographic co-ordinates: 46ํ5' N, 22ํㅜㄴ E). The sample was taken by one of us S.I. accompanied by J. Notemboom and O.T. Moldovan on 26 of September 2000 from a well in the lower terrace of Crișul Repede, at about $20 \mathrm{~m}$ from the river (Iepure 2007).

- Șuncuiuş (SU) about $20 \mathrm{~km} \mathrm{NW}$ of Bulz, Bihor County (approx. geographic co-ordinates: 46059' N, $\left.22^{\circ} 31^{\prime} \mathrm{E}\right)$. The material was sampled by one of us D.L.D. accompanied by D. Dancau and I. Tabacaru on 28 of July 1967 from a well dug in alluvial sediments of the river.

Additionally, few specimens collected from groundwater habitats at two other sites in the north-western and south-western Romania (Fig. 1) were selected for inclusion in the descriptive comparison of the valve morphology, however, this material is not used in statistical analysis:

- Sighiştel (SG), ca. $70 \mathrm{~km}$ NE from Oradea, Bihor County (approx. geographic co-ordinates: 47ํㅜㅇ' $\mathrm{N}$, $\left.22^{\circ} 31^{\prime} \mathrm{E}\right)$. The material was sampled by one of us D.L.D. accompanied by D. Dancau and I. Tabacaru on 12 of July 1969 from a well F3 that gives direct access to the groundwater of the Sighiştel Valley trough which the Crişul Negru river flows.

- Isverna (IS), ca. $40 \mathrm{~km} \mathrm{~N}$ from Drobeta-Turnu Severin, Mehedinți County (approx. geographic co-ordinates: $45^{\circ} 00^{\prime} \mathrm{N}, 22^{\circ} 36^{\prime} \mathrm{E}$ ). The material was sampled by one of us D.L.D. accompanied by E. Serban and D. Dancau on 21 of August 1967 from the hyporheal at the depth of ca. $30 \mathrm{~cm}$ of the Cosiustea stream, a resurgence of the Isverna Cave.

\section{Data acquisition and morphometric analysis of the valves}

Eight female left valves for each of the four populations subjected to statistical comparison (AL, AR, BU, $\mathrm{SU}$ ) were photographed with a NIKON camera and further valve outlines were digitised using TPS-dig software (Rohlf 2003). For the two other studied populations only three (IS) or two (SG) valves were available for our analysis. Additionally, a scanned valve of a C. vavrai female from a bog near Gentilino on the southern foot of the Swiss Alps (Fig. 1) figured in Kaufmann's (1900b) original description (cf. here Fig. 2B) was digitised and also integrated in the data set to relate the investigated populations to the topotype specimens of the species Fig. $5 \mathrm{E}$.

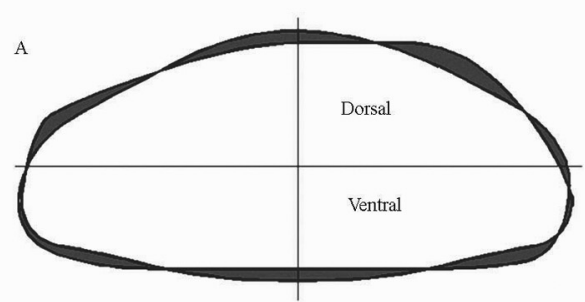

B

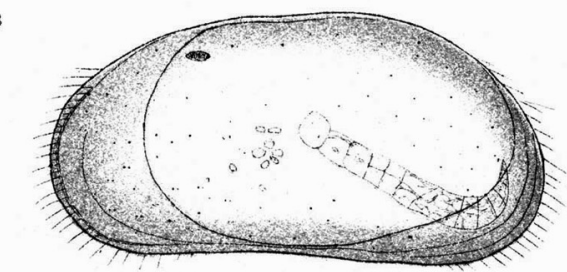

C

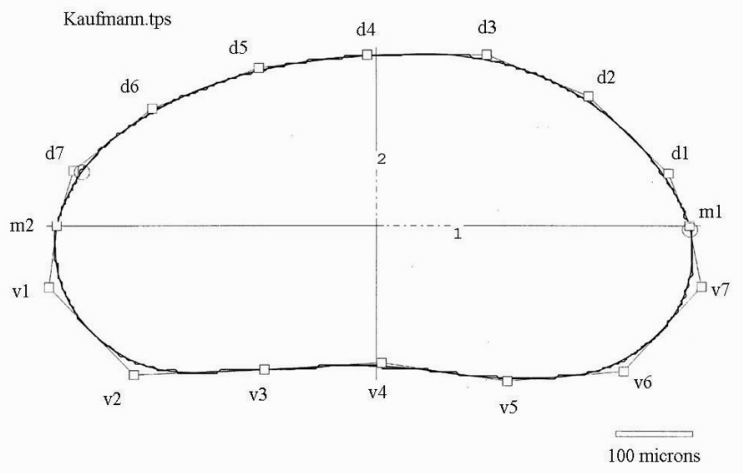

Number of iterations: 100

Mean error: $0.442(0.05 \%)$ dorsal $/ 0.586(0.07 \%)$ ventral

Maximum error: $2.960(0.36 \%)$ dorsal / $3.153(0.38 \%)$ ventral

Fig. 2. A - Area deviation for superimposed outlines of two hypothetical valves; B - Left valve of Cryptocandona vavrai from Gentilino (from Kaufmann 1900b); C - Reconstruction of the outline of the original Kaufmann's drawing of the C. vavrai valve shown in Fig. 2B using the Linhart's B-spline algorithm (symbols mark the position of the control points).

The geometric morphometrics analysis of the outlines was performed using the Linhart's B-spline algorithm computed with MORPHOMATICA software 1.6 (Brauneis et al. 2006, Neubauer 2007). This procedure allows one to evaluate the area deviation between two superimposed outlines for amount of disparity either in their total shapes or only in their dorsal or ventral halves (Fig. 2A). The approximation of the maximum error of the fitted mathematical curve to the digitised outline for each specimen in the studied material was bellow $1 \%$ ( $c f$. Fig. 2C) which represents an excellent result. Further, to avoid differences between the valve size, the outline approximations were ,normalised for the area" by the function implemented in MORPHOMATICA (Brauneis et al. 


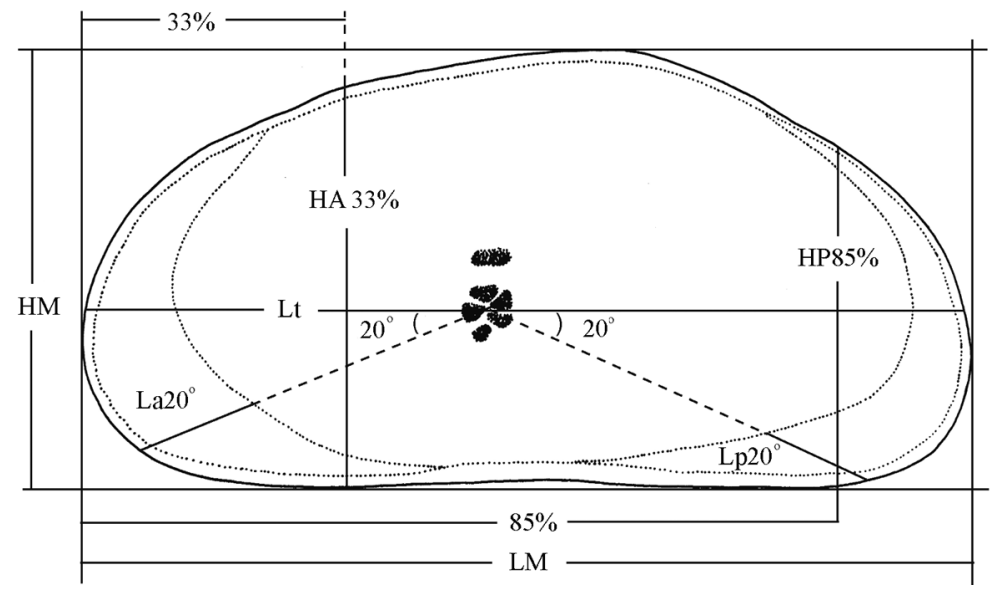

Fig. 3. Measurements taken on valves to analyse size and shape differences between the studied populations.

2006). Thus, all computed outlines encircled an equal area. A virtual mean outline (consensus shape) was computed from the data of individual outlines for each population and further used in pair-wise comparisons between other consensus outlines and the outline of the valve figured by Kaufmann (1900b).

Additionally, several linearmeasurements were taken on valves to supplement the differential comparison of the valve morphology between the studied populations. Acronyms of these measurements are given here and further indicated in Fig. 3 to assist in interpreting results: a) LM the maximum valve length, b) $\mathrm{HM}$ - the maximum height, c) $\mathrm{HP} 85 \%$ - the posterior height at $85 \%$ of LM, d) HA33\% - the anterior height at $33 \%$ of LM, e) La20 $0^{\circ}$ - the width of the calcified inner lamella anteriorly (including the fused zone with the radial pore canals) along a transect starting from the centre of the muscle scars bundle and running towards the outer anterior margin of the valve at the $20^{\circ}$ angle to a transect $\mathrm{Lt}$ (a line going through the centre of the muscle scars bundle and connecting anterior and posterior valve margin), f) $\mathrm{Lp} 20^{\circ}-$ the width of the calcified inner lamella posteriorly, measured analogously to La20 $0^{\circ}$ (cf. Fig.3). Furthermore, five ratios (indexes) of these measurements were calculated and expressed as percentages: a) HM / LM, b) HP85\% / HM, c) HA33\% / HM), d) La20 / $\mathrm{LM}$, and e) Lp20\%/LM. Finally, some basic statistics, as the arithmetic mean, standard deviation (SD) and the range (minimum-maximum) is also provided for these data sets.

\section{Abbreviations for the morphology of limbs}

The names and acronyms (and their combinations) for limbs, segments, claws and setae were used mostly according to Meisch (2000):
A2 - second antenna, A2EI- first endopodite of A2, co - outer of two postero-distal setae on A2EI, CR - caudal ramus (previously called furca), CRAM - anterior margin of $C R, G_{a}$ - anterior claw of $C R, G_{M}\left(G_{m}\right)$ - major (minor) claw on terminal endopodite of $A 2, G_{p}$ - posterior claw of $\mathrm{CR}, \mathrm{G}_{1-3}$ - three anterior and internal claws on penultimate endopodite of $\mathrm{A} 2, \mathrm{~h}_{1} \mathrm{~L} 7$ - short seta on terminal endopodite of $\mathrm{L} 7, \mathrm{~h}_{2} \mathrm{~L} 6$ - terminal claw on $\mathrm{L} 6$, $h_{2} L 7-$ medium seta on terminal endopodite of $L 7, h_{3} L 7$ - large seta on terminal endopodite of L7, L6 - walking leg (6th limb), L6EII - second endopodite of L6, L7 cleaning leg (7th limb), L7EI - first endopodite of L7, $\mathrm{s}_{\mathrm{a}}\left(\mathrm{s}_{\mathrm{p}}\right)$ - anterior (posterior) seta of CR, $\mathrm{s}_{\mathrm{p}}-\mathrm{G}_{\mathrm{p}}$ - distance between insertion points of $s_{p}$ and $G_{p}$ on CR, Y - aesthetasc on A2EI. For other abbreviations consult Meisch (2000).

\section{Biometric analysis of limbs}

Eight adult females from both the BU and AR populations, whereas 14 females from the SU and four from $\mathrm{AL}$ populations were used in morphological analysis of the limbs. The morphological variability was examined on dissected females mounted in glycerine on glass slides using a transmitted light microscope NIKON Eclipse E-200 at the magnification of $400 \times$. Line drawings were made using a microscope fitted with a drawing tube. A total of 20 different linear distances (lengths of all setae, aesthetascs, claws and segments mentioned in the list of abbreviations presented above) was taken on each of 34 females using an eyepiece micrometer with an accuracy of $2.5 \mu \mathrm{m}$. The lengths were measured according to the model proposed by Broodbakker \& Danielopol (1982). The obtained distance measurements were further converted into 16 ratios (seven traits on $\mathrm{A} 2$, one on $\mathrm{L} 6$, three 
on L7 and five on CR). For each variable (ratio) its mean, range (min-max values) and standard deviation (SD) were calculated. These ratios are defined and listed in Table 4 and 5 .

\section{Statistical analyses}

Beside basic statistics (as the arithmetic mean, SD, min-max range and $95 \%$ confidence limit), multivariate analyses were performed on the data set in order to test the morphological disparity of the valve shape within and among populations. A matrix of pair-wise dissimilarities obtained in MORPHOMATICA (Brauneis et al. 2006) was used for non-metric multidimensional scaling (N-MDS) and one-way ANOSIM (analysis of similarities) run by the PRIMER 6 package (Clarke \& Gorley 2006). ANOSIM is a non-parametric randomisation method, analogous to the parametric one-way ANOVA, which evaluates the degree of dissimilarities among pairs of populations (Clarke \& Warwick 2001). As a rule of thumb, values of the R statistic in one-way ANOSIM larger than 0.75 for the degree of dissimilarity of two groups of items express a clear separation among the populations (Clarke \& Gorley 2006). This can be checked also with the graphical representations resulted from N-MDS.

The pattern of valve disparity in the morphospace within populations was estimated using the mean pair-wise dissimilarity of valve areas (MPD), an index that is similar to that used by Ciampaglio et al. (2001) and by Iepure et al. (2007). When the MPD value is presented with the surrounding confidence limits (95\% CL) it gives an idea of the degree of variability of the valve-shapes within one population. The $95 \%$ CLs were computed by bootstrapping with the replacement and 5000 permutations using the software package which accompanies the "Ecological methodology" text book of Krebs (1999).

Discriminant function analysis (Manly 1998) was performed on the distance measurements of limbs by STATISTICA for Windows 5.1 programme (StatSoft, Inc. 2007) in order to determine if females could be accurately classified by sampling site based on the soft parts morphology and if so, to identify which of these traits were important in distinguishing between the populations. Out of all 16 calculated ratios, in the discriminant analysis we used only 14 (listed in Table 6) which complied with the assumptions of this analysis, i.e.: normal distribution (tested by Kolmogorov-Smirnov test), homogeneity of variances (tested by Levene test), correlations between means and variances (examined by inspecting the descriptive statistics) and redundancy of variables (by computation routinely implemented in the STATISTICA menu).

\section{Results}

\section{Valve shape disparity}

The original description of the left valve of $C$. vavrai in Kaufmann (1900b) points out an approximately rectangular form of $0.85 \mathrm{~mm}$ length ( $c f$. here Fig. 2B-C, Fig. $5 \mathrm{E})$, with maximum height situated in the posterior part and reaching $50.5 \%$ of the maximal length of the valve. The central part of the dorsal margin slightly inclined towards the anterior part, the index HA33\%/HM exceeding 95 . The posterior margin, widely rounded, the index HP85\%/HM amounting to 82.8. The ventral margin slightly concave in its central part. Width of the calcified inner lamella anteriorly approaching 18.9 as expressed by the $\mathrm{La} 20^{\circ} / \mathrm{LM}$ index, while posteriorly this lamella less developed, $\mathrm{Lp} 20^{\circ} / \mathrm{LM}$ index = ca. 15 .

The individuals of Arcine (AR) (Fig. 4C) resemble the topotype female from Gentilino described by Kaufmann (1900b). Maximal length of AR valves amounts to 0.77-0.87 mm, while HM ranging between $0.38-0.42 \mathrm{~mm}$ (Table 1) is located at mid-length or just in front of mid-length at about $47-51 \%$ of LM. These ranges as well as ranges of the other indexes $\mathrm{HP} 85 \% / \mathrm{HM}$, $\mathrm{La} 20^{\circ} / \mathrm{LM}$ (Table 1) and HA33\%/HM, Lp20\%/LM lay closely to those values of the Gentilino specimen. The mean virtual AR left valve (Figs. 5C, 6A) differs only slightly in the ventral and posterior part from the Gentilino valve being somewhat more elongated and having more straight ventral margin.

The specimens from Alas (AL) have the valve shape similar to that of the AR specimens (Figs 4D, 5D, 7A, Table 1), i.e. the rounded dorsal part, the range of $\mathrm{HM}$ between $0.39-0.42 \mathrm{~mm}$, the position of HM located at about $47-51 \%$ of the LM as well as the width of the inner lamella anteriorly $\left(\mathrm{La} 20^{\circ} / \mathrm{LM}=17-18\right)$ and posteriorly $\left(\mathrm{Lp} 20^{\circ} / \mathrm{LM}=\right.$ ca. 15$)$. The HM/LM ratio of the former individuals is slightly lower than that of AR (Table 1), while the HP85\%/HM is larger which determines slightly less rounded dorsal margin of AL valves (Fig. 7A). The posterior part of AL valves is widely rounded, while the ventral part is slightly concave with no variation. Some of the specimens are longer than those of AR and Gentilino (Table 1), which may explain the more elongated aspect of the virtual mean left valve (Fig. 5D) as compared to the Gentilino valve (Fig. 6B).

The females from Bulz (BU) display the carapace with usually arched dorsal part (Figs 4A, 5A). The length of 


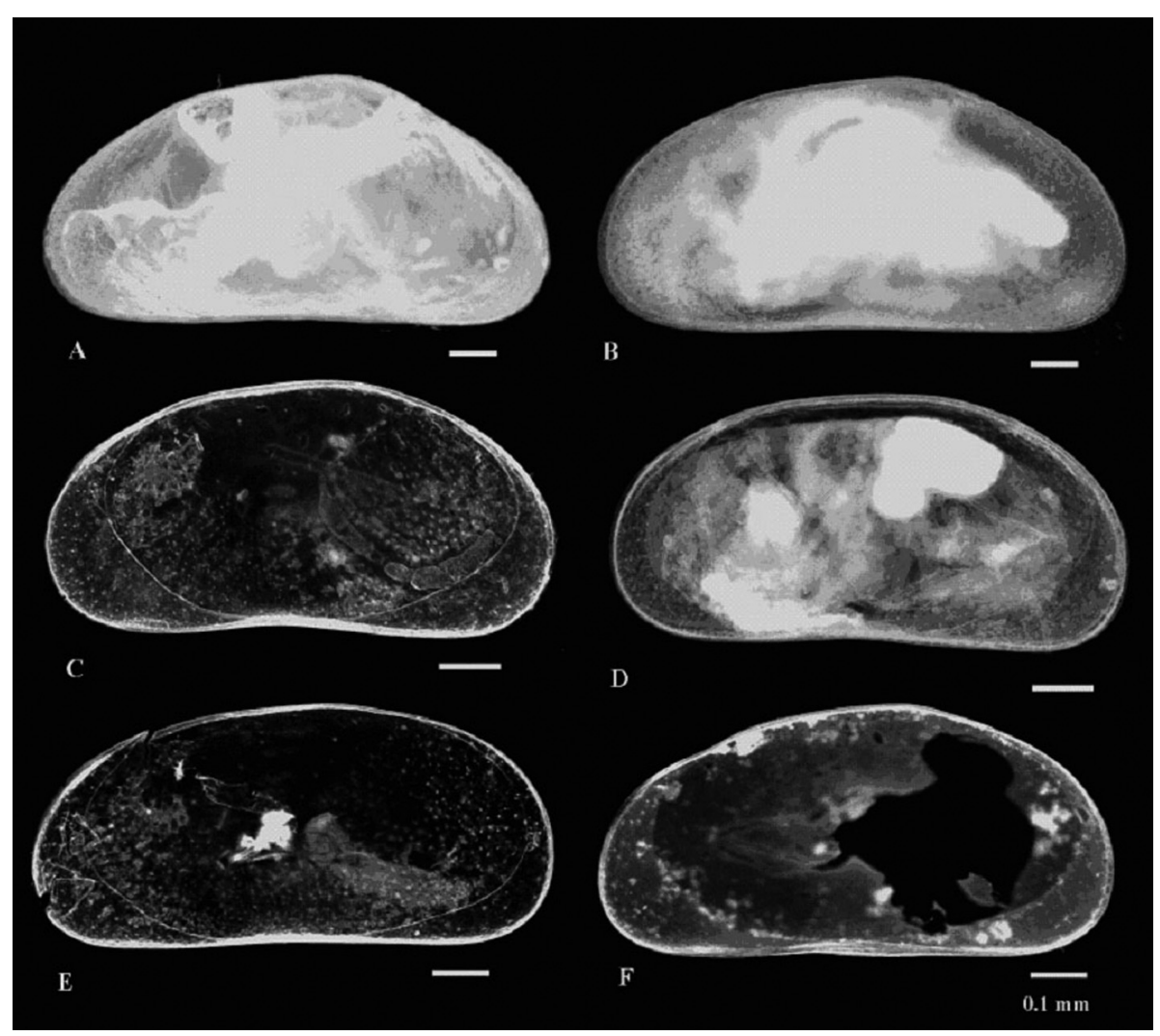

Fig. 4. Lateral view of carapaces and valves (anterior to the left) of females from various populations belonging to the Cryptocandona vavrai lineage: A - Bulz (C. racovitzai sp. nov.), B - Şuncuiuş (C. racovitzai sp. nov.), C - Arcine (C. vavrai s. str.), D - Alas, (C. vavrai s. str.), E Isverna (C. vavrai s. 1.), F - Sighiştel (C. racovitzai sp. nov.).

the valves approaches $0.97-1.09 \mathrm{~mm}$ and the HM/LM ratio ranges between $47-53$ (Table 1 ). The greatest height lays in the posterior third, located at about $53-55 \%$ of the valve LM. All the specimens show the ventral margin of the left valve almost straight.

The specimens from Șuncuiuş (SU) show similar shape of the left valves to those of the BU (Figs 4B, 5B). The greatest height of the valves ranges between $0.48-0.51 \mathrm{~mm}$ (Table 1) and is located behind mid-length at about $52-56 \%$ of the LM. The ventral margin of the LV is straight in all specimens, as in those from the previously described population.

Both, SU and BU samples display larger valves as compared to the previously described two populations of AR and AL ( $L M>0.97 \mathrm{~mm}$ versus $\mathrm{LM}<0.90 \mathrm{~mm}$ for $\mathrm{AL}$ and AR, Table 1). The dorsal margin of the valves of the former pair is more elevated, the postero-dorsal side more angular and the ventral margin straight (Fig. 4A-B). The values for the HP85\%/HM index are inferior to 80 (this index $>80$ for AR and AL, Table 1), the inner lamella less developed both anteriorly, $\mathrm{La} 20^{\circ} / \mathrm{LM}<16$ (for $\mathrm{AL}$ and AR this index $>16$, Table 1), and posteriorly, Lp20\% $\mathrm{LM}=12.7-14.0$ (for AL and AR this index $\geq 15$ ). There is no difference between the general shape (i.e. the consensus outlines) of SU and BU valves (Fig. 5A-B, 7B). A comparative examination by superimposing the consensus outlines from SU on the outline of the female from Gentilino (Fig. 6C) shows marked differences existing mainly on the dorsal part, $\mathrm{SU}$ (and $\mathrm{BU}$ ) valves being significantly higher, with the postero-dorsal margin straighter than their homologue segments of both the Swiss and French valves (Fig. 6C, 7C).

Furthermore, the characteristics of a few available valves from Sighiştel (SG) and Isverna (IS) are described bellow. Two females available from the SG site appeared to be more similar in valve shape to the BU and SU specimens than to those from the French sites. The dorsal margin of the SG female valves is arched, LM approaches $0.95 \mathrm{~mm}$ while $\mathrm{HM}$ amounts to $0.47 \mathrm{~mm}$ (Table 1) and is located just behind mid-length at about 
Table 1. Differential comparison of the valve size and shape descriptors between females from the studied populations (sample sizes: IS $=3$, SG $=2, \mathrm{AR}=8$, whereas $\mathrm{AL}, \mathrm{BU}$ and $\mathrm{SU}=8$ except for the index $\mathrm{La} 20^{\circ} / \mathrm{LM}$ for which $\mathrm{AL}=6, \mathrm{BU}=6$ and $\mathrm{SU}=10$ valves ).

\begin{tabular}{cccccccc}
\hline & & $\mathrm{AL}$ & $\mathrm{AR}$ & $\mathrm{BU}$ & $\mathrm{SU}$ & $\mathrm{SG}$ & $\mathrm{IS}$ \\
\hline $\mathrm{LM}$ & Mean & 0.86 & 0.83 & 1.03 & 1.02 & 0.95 & 0.92 \\
$(\mathrm{~mm})$ & $\mathrm{SD}$ & 0.03 & 0.03 & 0.04 & 0.01 & 0.00 & 0.06 \\
& Range & $0.80-0.90$ & $0.77-0.87$ & $0.97-1.09$ & $0.99-1.02$ & 0.95 & $0.85-0.95$ \\
\hline $\mathrm{HM}$ & Mean & 0.41 & 0.41 & 0.50 & 0.50 & 0.47 & 0.44 \\
$(\mathrm{~mm})$ & $\mathrm{SD}$ & 0.01 & 0.01 & 0.03 & 0.009 & 0.00 & 0.04 \\
& Range & $0.39-0.42$ & $0.38-0.42$ & $0.47-0.56$ & $0.48-0.51$ & 0.47 & $0.38-0.45$ \\
\hline HM/LM & Mean & 48 & 49 & 49 & 48 & 49 & 46 \\
$(\%)$ & SD & 1 & 1 & 2 & 1 & 0 & 1 \\
& Range & $46-50$ & $47-51$ & $47-53$ & $48-50$ & 49 & $45-47$ \\
\hline HP85\%/HM & Mean & 82.9 & 81.3 & 77.0 & 77.2 & 77.3 & 83.8 \\
$(\%)$ & SD & 0.97 & 0.91 & 1.37 & 1.43 & 0.42 & 0.49 \\
& Range & $81.1-84.9$ & $80.3-82.8$ & $74.0-78.5$ & $76.0-79.9$ & $77.0-77.6$ & $83.4-84.1$ \\
\hline La20 $/$ LM & Mean & 17.6 & 17.9 & 14.5 & 14.2 & 16.1 & 14.4 \\
$(\%)$ & SD & 0.35 & 0.67 & 0.53 & 0.32 & 0.00 & 0.23 \\
& Range & $17.0-18.0$ & $17.1-18.8$ & $13.6-15.2$ & $13.8-14.9$ & 16.1 & $14.3-14.7$ \\
\hline
\end{tabular}

$51-53 \%$ of LM (Fig. 4F). The values for both, the index $\mathrm{HP} 85 \% / \mathrm{HM}=\mathrm{ca} .76$ and $\mathrm{La} 20^{\circ} / \mathrm{LM}<17$, are very similar to those of the BU and SU females.

Contrary to the SG specimens, three studied females from the IS site seemed to be closer in their valve shape to the individuals from France than to those from the other Romanian sites. The valves of the IS females are elongated with $\mathrm{LM}=0.85-0.95 \mathrm{~mm}$, HM ranging between $0.38-0.45 \mathrm{~mm}$ and being located at mid-length or just in front of mid-length at about $38-50 \%$ of the LM and with posterior margin widely rounded (Fig. 4E, Table 1). The posterior height as measured by the index HP85\%/HM varies between 83.6 and 84.1, whereas the anterior height HA33\%/HM equals to ca. 94. The width of the inner lamella anteriorly as expressed by the index $\mathrm{La} 20^{\circ} / \mathrm{LM}$ index $=14.3-14.7$ (Table 1). The IS valves resemble in shape those of AL and AR, but are larger in size and apparently more elongated.

The differences between the left valve outlines of the analysed specimens when expressed as N-MDS plots in a three-dimensional morphospace separately for the total area deviation and for its dorsal half (Fig. 8A and 8B, respectively) show a separation of the French populations from the Romanian ones. It may be noticed in the "total surface" plot (Fig. 8A) that the valve of C. vavrai from Gentilino is situated reasonably far away from the other specimens of the four studied populations. How- ever, this is not the case for the "dorsal half" plot, where the Gentilino item clusters with the AR ones.

The mean pair-wise disparity values with the accompanying $95 \%$ confidence limits of the valves for the four populations are presented in Table 2. This comparison indicates that populations of BU and AR display high values around 20, with a wide range of the confidence limits (especially the former population). The opposite applies to the AL and SU populations, for which the MPD and their 95\% CL are much lower. The degree of the variability of the valve disparity for these populations is also visible in the 3D morphological space represented as Euclidean distances in the N-MDS plot (Fig. 8). Here again one can notice that the BU and AR are spread over a wide space.

The one-way ANOSIM test was further applied to the four populations, in order to check how well they are pair-wise separated (Table 3). The specimens of the BU and SU populations with their arched or quasi-angular dorsal margin are clearly separated from those with more rounded dorsal margin of the AR and AL populations. When compared the pair-wise disparity of the total area deviation of the valves (Table 3 -Area total) one notices that the $\mathrm{R}$ statistic is higher than 0.75 for the pairs AR-BU,AR-SU and for the AL-BU,AL-SU. For the pair of the French and the pair of the Romanian populations however, the $\mathrm{R}$ value is low, $(0.16-0.31)$ which indicates 


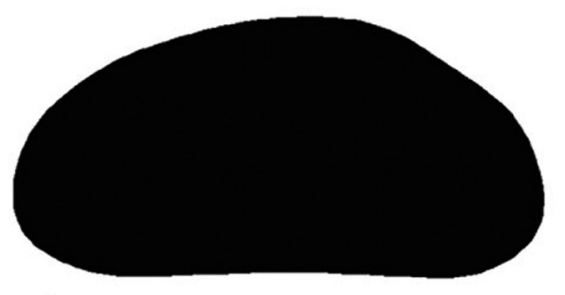

A

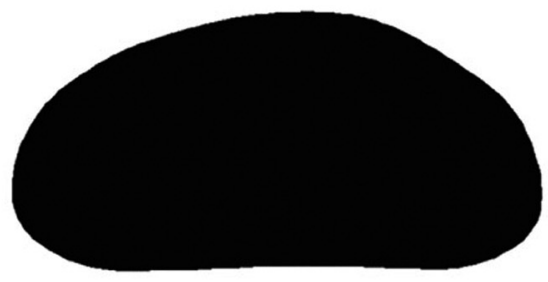

B

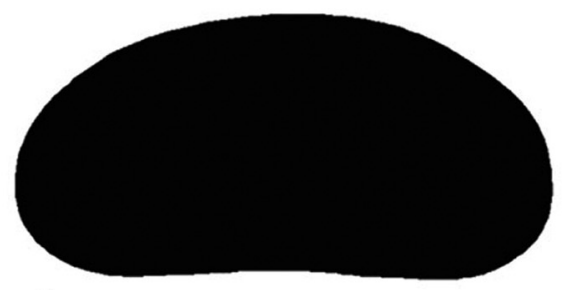

$\mathrm{C}$
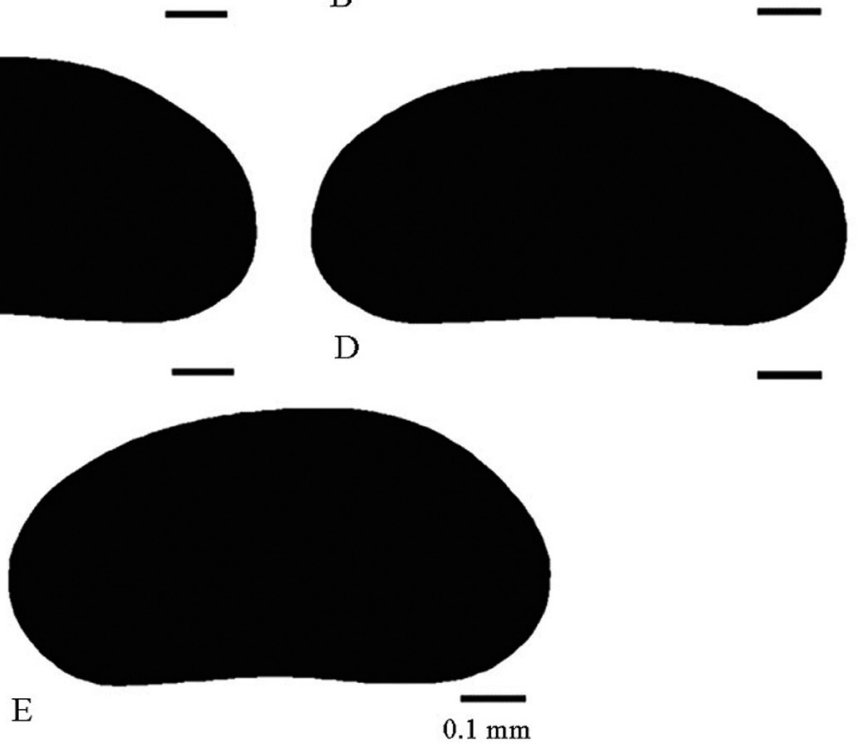

Fig. 5. Virtual mean (consensus) shape for the left valves (anterior to the left) of females from: A - Bulz, B - Şuncuiuş, C - Arcine, D - Alas (A-B - C. racovitzai sp. nov., C-E - C. vavrai).

close similarities of the valve shape between the AR-AL and BU-SU pairs.

The analysis among the four populations, performed separately for the dorsal and ventral areas of the valves, allows pointing out that the dorsal part is much more responsible for the differentiation of the two groups, i.e. the French populations (AL and AR) vs. the Romanian ones (BU and SU), than the ventral part. The R values which characterise the degree of disparity of the dorsal half of the valves reflect more or less the same pattern as those performed for the "Area total" (Table 3-Area total vs. Area dorsal). The only exceptions are the reasonably low $\mathrm{R}$ values (0.66-0.68) for the AR-BU and AR-SU pairs, most likely due to a slightly higher dorsal margin of the AR specimens as compared to those of AL (Fig. 4C-D, 5C-D, 7A). Finally, the R values for the "Area ventral" (Table 3) appear to segregate two groups of populations. The $\mathrm{R}$ values for the pairs of AR-AL and BU-SU are close to zero pointing out a quasi perfect similarity of the specimens, while for the other pairs these values are much higher (between 0.59 and 0.82) indicating the higher differences between the ventral valve sides between these four populations.

\section{Morphological variability of the limbs}

The measurements of the 16 limb traits are summarised in Tables 4 and 5. Descriptive statistics show considerable differences in the arithmetic means of some characters among the four studied populations, however the ranges overlapped and as such no obvious morphological discontinuities were observed. However, it has to be mentioned that females from BU and SU are characterised by the length reduction of some claws and setae as compared with females of AR and AL. The most prominent differences refer to the relative length of the antennal claw $\mathrm{G}_{2}$ and the posterior claw $\mathrm{G}_{\mathrm{p}}$ on caudal ramus (Table 4 an 5). Less manifested discrepancy is visible when comparing the relative length of two other antennal claws $G_{1}$ and $G_{m}$ as well as the $h_{1}$ seta on the terminal segment of L7 and the anterior claw $\mathrm{G}_{\mathrm{a}}$ on CR (Table 4 and $5)$. 

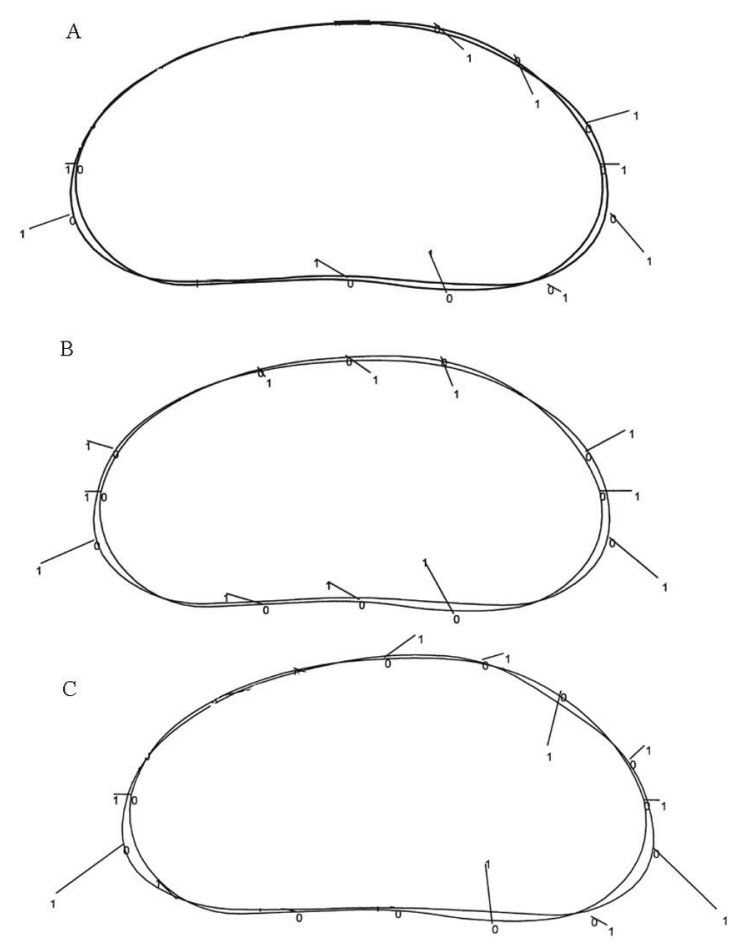

Fig. 6. Superimposition of the consensus valve outline (a mean specimen) of a studied population (outline coded as 1) on the outline of the valve of the $C$. vavrai topotype female from Gentilino (coded as 0 ) showing disparity of the valve shapes between the topotypical and the studied populations: A Gentilino versus Arcine, B - Gentilino versus Alas, C - Gentilino versus Şuncuiuş.

The discriminant function analysis applied on 14 of these traits allowed distinguishing the populations morphometrically (Fig. 9). Discrimination between the populations was highly significant: Wilks' lambda $=0.0026$, $\mathrm{F}(42,51)=7.906, \mathrm{p}<0.001$. The standardised coefficients for the first three roots (canonical functions), which accounted for $100 \%$ of the explained variance are listed in Table 6, whereas the squared Mahalanobis distances between the studied populations and the F values together with the probability levels are presented in Table 7. The first canonical function (Root 1) accounted for $75 \%$ of the explained variability and discriminated evidently between two pairs of populations. The first, consisting of the BU and SU populations which had the most negative values, is clearly separated to the left, while the second group of the AL and AR populations appears on the right-hand side of the scatter plot (Fig. 9A). The separation is marked mainly by the relative lengths of the claw $\mathrm{G}_{\mathrm{p}}$ and the distance $\mathrm{s}_{\mathrm{p}}-\mathrm{G}_{\mathrm{p}}$, both on $\mathrm{CR}$ (Table 6) as
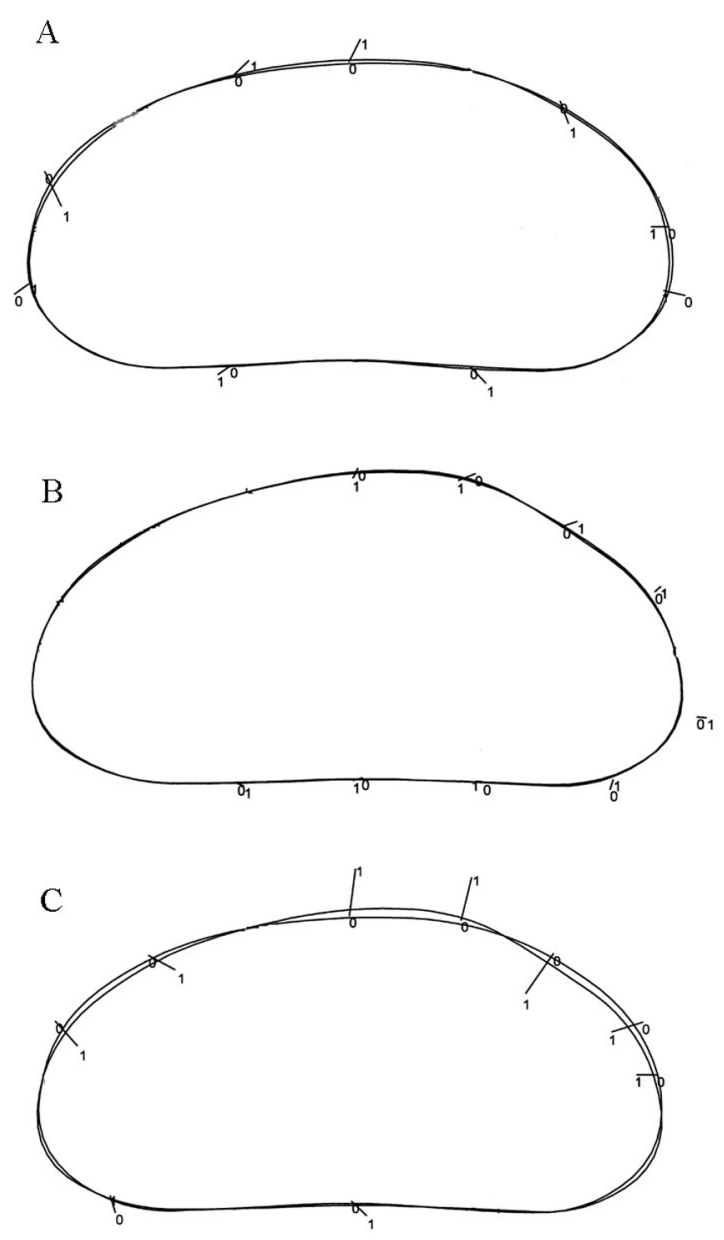

Fig. 7. Valve shape disparity between the studied populations presented as superimposition of the consensus valve outlines (mean specimens): A - AL (coded as 0) vs. AR (coded as 1), B SU (0) vs. BU (1), C - AL (0) vs. SU (1).

well as of the claw $\mathrm{G}_{2}$ of $\mathrm{A} 2$. The second canonical function (Root 2) accounting for $17 \%$ of the explained variability provided discrimination mainly between the AR and AL females, the latter having the most negative values (Fig. 9A). This was marked mainly by the relative lengths of $G_{1}$ claw on $A 2$ as well as of $s_{p}$ seta and $G_{p}$ claw on CR (Table 6). Finally, the third canonical function $(8 \%$ of the explained variability) offered some separation between the BU and SU females (Fig. 9B), however, the discrimination was not as successful as that provided by the Root 1 or Root 2 (Fig 9A). The Root 3 was most heavily loaded by the relative lengths of the $\mathrm{A} 2$ terminal claws $\mathrm{G}_{\mathrm{m}}$ and $\mathrm{G}_{\mathrm{M}}$ (Table 6). 
A

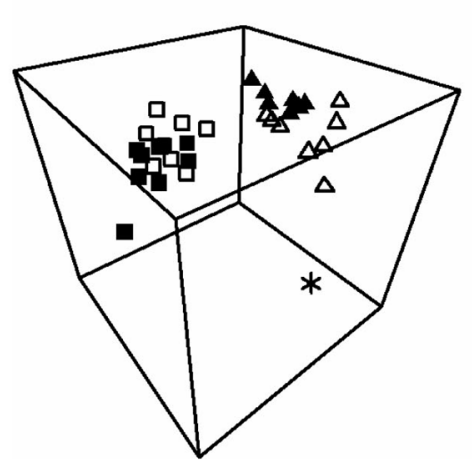

B

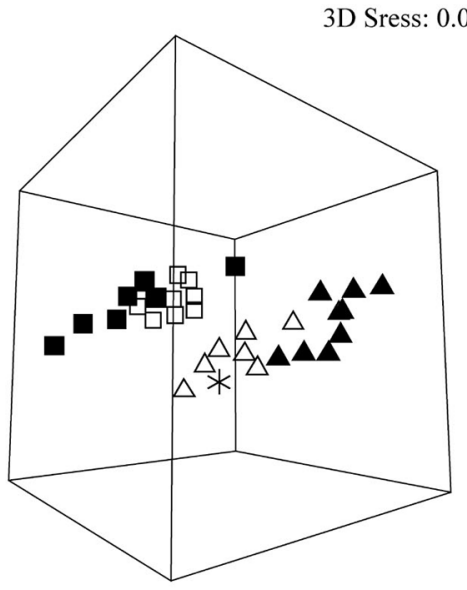

Fig. 8. Ordination of the females from four studied populations and the topotype specimen from Gentilino (GT) by non-metric multidimensional scaling (N-MDS) mapped in 3D plots: $\mathrm{A}$ - the total area morphospace, $\mathrm{B}$ - same for the dorsal area.

Table 2. Mean pair-wise disparity values (MPD) of the valve shape within four studied populations (number of combinations in each case $=28$ )

\begin{tabular}{llc}
\hline & MPD & CL95\% \\
\hline AL & 14.90 & $12.69-17.25$ \\
AR & 20.45 & $17.90-23.00$ \\
BU & 20.26 & $16.80-23.74$ \\
SU & 12.57 & $11.36-13.79$ \\
\hline
\end{tabular}

In conclusion, despite the significant statistical differences observed between the limb morphology of the studied populations and their groups, there is still considerable overlap in several measured variables of the individual females. Thus, it is hardly possible to assign unambiguously any single female to a particular geo- graphic area on the basis of any of the used linear distances alone. However, it could be more feasible when employing a combination of these variables through comparative studies on larger sample sizes.

\section{Description of Cryptocandona racovitzai sp. nov.}

Although no obvious morphological discontinuities in the limb morphology were observed between the studied populations, the revealed substantial differentiation in the valve size and shape between the French (AL and AR) and Romanian (BU and $\mathrm{SU}$ ) populations as well as between the latter and the topotype specimen of $C$. vavrai from Gentilino has not to be considered to rank within the variability range of one species. Hence, the Romanian populations from the SU, BU as well as SG sites are deemed here to deserve a separate taxonomic status and are describe below as a new species.

Family Candonidae Kaufmann, 1900

Subfamily Candoninae Kaufmann, 1900

Genus Cryptocandona Kaufmann, 1900

Cryptocandona racovitzai sp. nov. (Fig. 4A, B, F, Fig. 5A-B, Fig. 10)

Type locality: Şuncuiuş, ca. $45 \mathrm{~km}$ SEE of Oradea, Bihor County, Romania, approx. geographic co-ordinates: 46-59' N, 2231' E (see section Material and Methods).

Type material: Holotype: a female with limbs dissected and mounted in glycerine on a permanent slide, valves stored dry in a micropalaeontological cell. Paratypes: ca. 20 females either mounted as dissected or undissected in glycerine or preserved in ethanol in toto as well as a bulk of empty valves stored dry in micropalaeontological cells. All the type specimens were collected by D.L. Danielopol on 28 of July 1967 from a well accessing to the groundwater of the Crişul Repede River at the type locality.

Deposition: the holotype as well as the paratype no 1 (a female dissected and stored as the holotype) and the paratype no 2 (a female in toto preserved in ethanol and kept in a glass tube) are housed in the collection of the Natural History Museum at Vienna, Department of Crustacea under no NHMW 23253 (holotype) and NHMW 23254 (paratypes no 1 and 2). The remaining specimens are lodged at the working collections of S.I., T.N. and D.L.D.

Derivation of name: The new species is named after Emil G. Racoviță (1868-1947), the Romanian naturalist who developed the modern biospeleology and founded 
Table 3. Results of the one way ANOSIM test for the differences (expressed by the R statistic values with the probability levels) in the total, dorsal and ventral area of the female valves between pairs of the studied populations.

\begin{tabular}{ccccccc}
\hline \multirow{2}{*}{ Populations } & \multicolumn{2}{c}{ Total area } & \multicolumn{2}{c}{ Dorsal area } & \multicolumn{2}{c}{ Ventral area } \\
\cline { 2 - 7 } & R statistic & P level (\%) & R statistic & P level (\%) & R statistic & P level (\%) \\
\hline AR - BU & 0.80 & 0.1 & 0.68 & 0.2 & 0.68 & 0.1 \\
AR - SU & 0.81 & 0.1 & 0.66 & 0.1 & 0.82 & 0.1 \\
AR - AL & 0.31 & 0.9 & 0.37 & 0.5 & 0.10 & 9.3 \\
BU - SU & 0.16 & 3.4 & 0.22 & 1.2 & 0.02 & 30.3 \\
BU - AL & 0.92 & 0.3 & 0.94 & 0.1 & 0.59 & 0.1 \\
SU - AL & 0.98 & 0.1 & 0.99 & 0.3 & 0.77 & 0.1 \\
\hline
\end{tabular}

Table 4. Differences in the relative length of various claws, setae and aesthetascs on A2 of females from four studied populations (sample sizes: $\mathrm{AL}=4, \mathrm{AR}=8, \mathrm{BU}=8$ and $\mathrm{SU}=14$ individuals).

\begin{tabular}{|c|c|c|c|c|c|}
\hline Variable & Statistic & $\mathrm{AL}$ & AR & $\mathrm{BU}$ & SU \\
\hline \multirow{3}{*}{ co / A2EI } & Mean & 0.73 & 0.61 & 0.67 & 0.72 \\
\hline & SD & 0.087 & 0.011 & 0.066 & 0.054 \\
\hline & Range & $0.64-0.84$ & $0.59-0.63$ & $0.55-0.76$ & $0.59-0.81$ \\
\hline \multirow{3}{*}{$\mathrm{G}_{1} / \mathrm{A} 2 \mathrm{EI}$} & Mean & 1.22 & 1.38 & 1.16 & 1.19 \\
\hline & SD & 0.066 & 0.052 & 0.064 & 0.053 \\
\hline & Range & $1.15-1.31$ & $1.27-1.45$ & $1.11-1.30$ & $1.12-1.28$ \\
\hline \multirow{3}{*}{$\mathrm{G}_{2} / \mathrm{A} 2 \mathrm{EI}$} & Mean & 0.77 & 0.78 & 0.65 & 0.68 \\
\hline & SD & 0.037 & 0.024 & 0.038 & 0.031 \\
\hline & Range & $0.73-0.82$ & $0.75-0.81$ & $0.59-0.70$ & $0.63-0.73$ \\
\hline \multirow{3}{*}{$\mathrm{G}_{3} / \mathrm{A} 2 \mathrm{EI}$} & Mean & 1.14 & 1.25 & 1.10 & 1.13 \\
\hline & SD & 0.120 & 0.072 & 0.061 & 0.059 \\
\hline & Range & $1.00-1.29$ & $1.12-1.35$ & $1.04-1.22$ & $1.05-1.24$ \\
\hline \multirow{3}{*}{$\mathrm{G}_{\mathrm{M}} / \mathrm{A} 2 \mathrm{EI}$} & Mean & 0.92 & 1.07 & 0.90 & 0.91 \\
\hline & SD & 0.050 & 0.016 & 0.041 & 0.056 \\
\hline & Range & $0.86-0.98$ & $1.05-1.09$ & $0.87-1.00$ & $0.76-1.00$ \\
\hline \multirow{3}{*}{$\mathrm{G}_{\mathrm{m}} / \mathrm{A} 2 \mathrm{EI}$} & Mean & 0.66 & 0.77 & 0.62 & 0.65 \\
\hline & SD & 0.065 & 0.022 & 0.030 & 0.034 \\
\hline & Range & $0.60-0.75$ & $0.75-0.81$ & $0.58-0.68$ & $0.56-0.69$ \\
\hline \multirow{3}{*}{ Y /A2EI } & Mean & 0.42 & 0.52 & 0.43 & 0.43 \\
\hline & SD & 0.044 & 0.020 & 0.018 & 0.038 \\
\hline & Range & $0.40-0.49$ & $0.49-0.55$ & $0.40-0.46$ & $0.33-0.47$ \\
\hline
\end{tabular}

Table 5. Differences in the relative length of various claws, setae and distances on L6, L7 and CR of females from four studied populations (sample sizes as in Table 4).

\begin{tabular}{|c|c|c|c|c|c|}
\hline Vari & Statistic & $\overline{\mathrm{AL}}$ & $\overline{A R}$ & $\mathrm{BU}$ & $\mathrm{SU}$ \\
\hline \multirow{3}{*}{$\mathrm{h}_{2} \mathrm{~L} 6$ / L6EII } & Mean & 2.78 & 2.57 & 2.99 & 2.63 \\
\hline & SD & 0.190 & 0.054 & 0.133 & 0.391 \\
\hline & Range & $2.50-2.90$ & $2.51-2.69$ & $2.80-3.18$ & $2.13-3.2$ \\
\hline \multirow{3}{*}{$\mathrm{h}_{1} \mathrm{~L} 7 / \mathrm{L} 7 \mathrm{EI}$} & Mean & 0.21 & 0.22 & 0.18 & 0.19 \\
\hline & SD & 0.014 & 0.019 & 0.022 & 0.020 \\
\hline & Range & $.20-0.22$ & $0.19-0.24$ & $0.14-0.20$ & $0.15-0.23$ \\
\hline \multirow{3}{*}{$\mathrm{h}_{2} \mathrm{~L} 7 / \mathrm{L} 7 \mathrm{EI}$} & Mean & 0.59 & 0.58 & 0.57 & 0.56 \\
\hline & SD & 0.033 & 0.036 & 0.067 & 0.068 \\
\hline & Range & $0.56-0.62$ & $0.54-0.63$ & $0.49-0.70$ & $0.44-0.7$ \\
\hline \multirow{3}{*}{$\mathrm{h}_{3} \mathrm{~L} 7 / \mathrm{L} 7 \mathrm{EI}$} & Mean & 1.62 & 1.85 & 1.67 & 1.60 \\
\hline & SD & 0.169 & 0.104 & 0.143 & 0.125 \\
\hline & Range & $1.44-1.82$ & $1.71-2.00$ & $1.37-1.84$ & $1.34-1.7^{7}$ \\
\hline \multirow{3}{*}{$\mathrm{s}_{\mathrm{a}} / \mathrm{CRAM}$} & Mean & 13 & 0.17 & 0.14 & 0.15 \\
\hline & SD & 009 & 0.011 & 0.015 & 0.021 \\
\hline & Range & $0.12-0.14$ & $0.15-0.18$ & $0.12-0.15$ & $0.11-0.18$ \\
\hline \multirow{3}{*}{$\mathrm{s}_{\mathrm{p}} / \mathrm{CRAM}$} & Mean & 0.13 & 0.17 & 0.12 & 0.15 \\
\hline & $\mathrm{SD}$ & 016 & 0.013 & 0.011 & 0.014 \\
\hline & Range & $0.11-0.14$ & $0.15-0.19$ & $0.10-0.13$ & $0.13-0.17$ \\
\hline \multirow{3}{*}{$\mathrm{G}_{\mathrm{a}} / \mathrm{CRAM}$} & Mean & 0.60 & 0.66 & 0.57 & 0.57 \\
\hline & D & 0.020 & 0.024 & 0.024 & 0.043 \\
\hline & Range & $0.57-0.62$ & $0.62-0.70$ & $0.53-0.60$ & $0.49-0.6$ \\
\hline \multirow{3}{*}{$\mathrm{G}_{\mathrm{p}} / \mathrm{CRAM}$} & Mean & 0.52 & 0.56 & 0.46 & 0.46 \\
\hline & SD & 0.013 & 0.025 & 0.020 & 0.031 \\
\hline & Range & $0.50-0.53$ & $0.50-0.58$ & $0.43-0.49$ & $0.40-0.5$ \\
\hline \multirow{3}{*}{$\begin{array}{l}\mathrm{s}_{\mathrm{p}}-\mathrm{Gp} / \\
\text { CRAM }\end{array}$} & Mean & 0.26 & 0.27 & 0.26 & 0.29 \\
\hline & SD & 0.002 & 0.010 & 0.026 & 0.028 \\
\hline & Range & 0.26 & $0.25-0.28$ & $0.21-0.30$ & $0.22-0.3$ \\
\hline
\end{tabular}



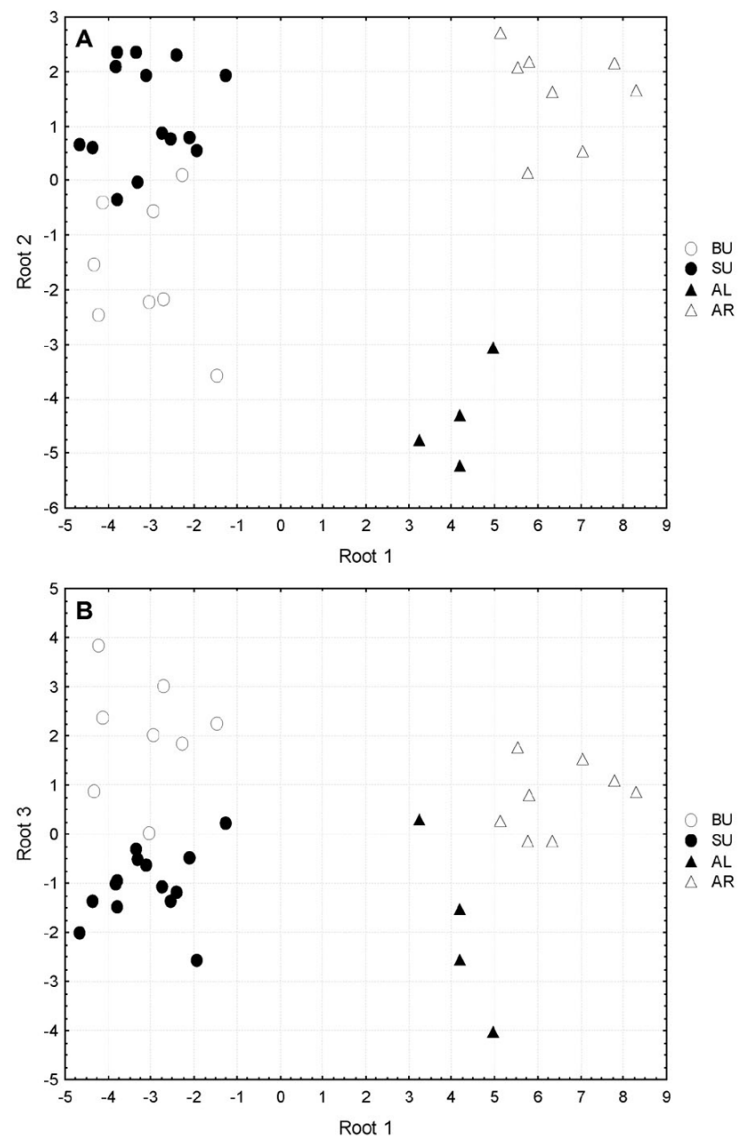

Table 6. Standardised coefficients for the first three roots (canonical functions) of the multiple group discriminant analysis based on the limb biometric data collected on females from four studied populations.

\begin{tabular}{|c|c|c|c|}
\hline Variable & Root 1 & Root 2 & Root 3 \\
\hline $\mathrm{G}_{1} / \mathrm{A} 2 \mathrm{EI}$ & -0.536 & 0.701 & -0.134 \\
\hline $\mathrm{G}_{2} / \mathrm{A} 2 \mathrm{EI}$ & 0.682 & -0.786 & -0.601 \\
\hline $\mathrm{G}_{3} / \mathrm{A} 2 \mathrm{EI}$ & -0.793 & -0.511 & -0.230 \\
\hline $\mathrm{G}_{\mathrm{M}} / \mathrm{A} 2 \mathrm{EI}$ & 0.442 & 0.443 & 1.100 \\
\hline $\mathrm{G}_{\mathrm{m}} / \mathrm{A} 2 \mathrm{EI}$ & -0.269 & -0.296 & -0.895 \\
\hline Y/A2EI & 0.365 & 0.110 & 0.805 \\
\hline $\mathrm{h}_{1} / \mathrm{L} 7 \mathrm{EI}$ & 0.469 & 0.539 & -0.448 \\
\hline $\mathrm{h}_{2} / \mathrm{L} 7 \mathrm{EI}$ & -0.356 & -0.319 & 0.092 \\
\hline $\mathrm{h}_{3} / \mathrm{L} 7 \mathrm{EI}$ & 0.033 & -0.353 & 0.588 \\
\hline $\mathrm{s}_{\mathrm{a}} / \mathrm{CRAM}$ & -1.013 & 0.379 & 0.139 \\
\hline $\mathrm{s}_{\mathrm{p}} / \mathrm{CRAM}$ & 0.912 & 0.708 & -0.283 \\
\hline $\mathrm{G}_{\mathrm{a}} / \mathrm{CRAM}$ & 0.003 & 0.161 & -0.126 \\
\hline $\mathrm{G}_{\mathrm{p}} / \mathrm{CRAM}$ & 1.868 & -0.791 & 0.251 \\
\hline $\mathrm{s}_{\mathrm{p}}-\mathrm{G}_{\mathrm{p}} / \mathrm{CRAM}$ & -1.419 & 0.532 & -0.662 \\
\hline Eigenvalue & 20.510 & 4.580 & 2.268 \\
\hline $\begin{array}{l}\text { Cumulative } \\
\text { proportion }\end{array}$ & 0.750 & 0.917 & 1.000 \\
\hline
\end{tabular}

Fig. 9. Scatter plots demonstrating discrimination by 14 biometric variables on limbs of 34 studied females grouped into four populations: A - the first discriminant function (Root 1) against the second (Root 2), B - the first discriminant function (Root 1) against the third one (Root 3$)$.

in Cluj (Romania) the world's first research institute specialised on the study of subterranean fauna. The name is to be treated as a noun in the genitive singular.

\section{Description of female}

Since the morphology of Cryptocandona racovitzai sp. nov. resembles much that of $C$. vavrai (for the emended diagnosis and detailed description of the latter species see Namiotko et al. 2005b), only brief description of the new species is provided below.

Cryptocandona racovitzai sp. nov. is a relatively large representative of the genus (carapace length $\geq 0.95 \mathrm{~mm}$, usually $>1 \mathrm{~mm}$ ) with valves elongated, dorsally weakly arched, and greatest height situated behind mid-length (at $51-56 \%$ of LM). Left valve overlapping right one along entire margin. Postero-dorsal margin of both

Table 7. Matrix of squared Mahalanobis distances listed above the diagonal and of the $F$ values (degrees of freedom 14, 17) together with probability levels $(* * *=\mathrm{p} \leq 0.001, * *=0.001<\mathrm{p} \leq 0.01)$ listed below the diagonal between the females from four studied populations.

\begin{tabular}{ccccc}
\hline & $\mathrm{AL}$ & $\mathrm{AR}$ & $\mathrm{BU}$ & $\mathrm{SU}$ \\
\hline $\mathrm{AL}$ & $\times$ & 48.253 & 76.602 & 83.981 \\
$\mathrm{AR}$ & $5.208^{* * *}$ & $\times$ & 104.303 & 94.546 \\
$\mathrm{BU}$ & $8.268^{* * * *}$ & $16.887^{* * *}$ & $\times$ & 17.337 \\
$\mathrm{SU}$ & $10.575^{* * *}$ & $19.482^{* * *}$ & $3.573 * *$ & $\times$ \\
\hline
\end{tabular}

valves sloping steeply, the HP85\%/HM index inferior to 80. Calcified inner lamella relatively well developed, the index $\mathrm{La} 20^{\circ} / \mathrm{LM}<16.5$, while that of $\mathrm{Lp} 20^{\circ} / \mathrm{LM}<14$ (Table 1, Figs. 4A-B, F, 5A-B, 10A-B). First antenna with 3rd ramus podomere lacking posterior seta (Fig. $10 \mathrm{E})$. Relative lengths of the A2 claws, co seta and the aesthetasc $\mathrm{Y}$ compared with the length of A2EI as: $\mathrm{G}_{1}=$ $1.11-1.30, \mathrm{G}_{2}=0.63-0.73, \mathrm{G}_{3}=1.04-1.24, \mathrm{G}_{\mathrm{M}}=$ $0.76-1.00, \mathrm{G}_{\mathrm{m}}=0.56-0.69$, со $=0.55-0.81, \mathrm{Y}=$ $0.33-0.47$, sensory part of this organ representing about 


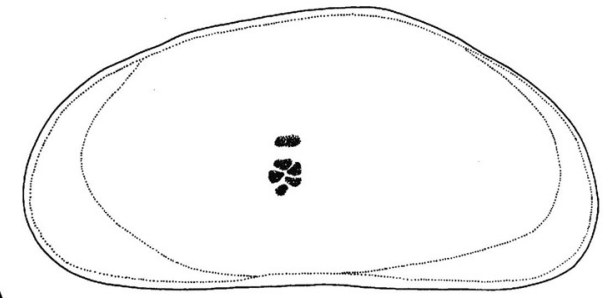

A
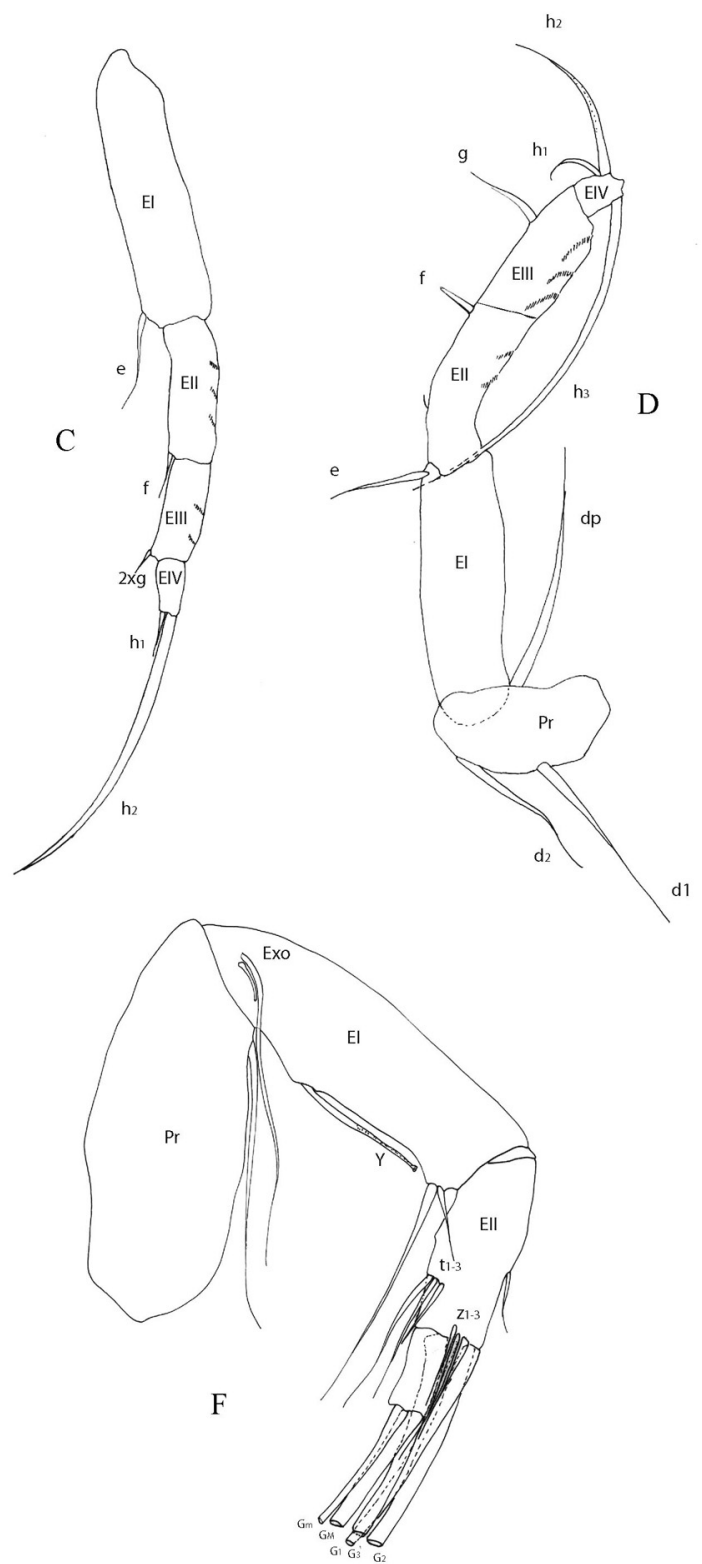

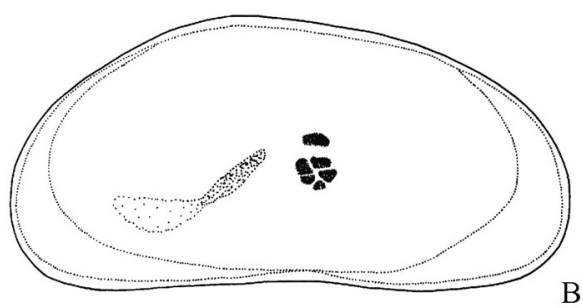

$\mathrm{B}$

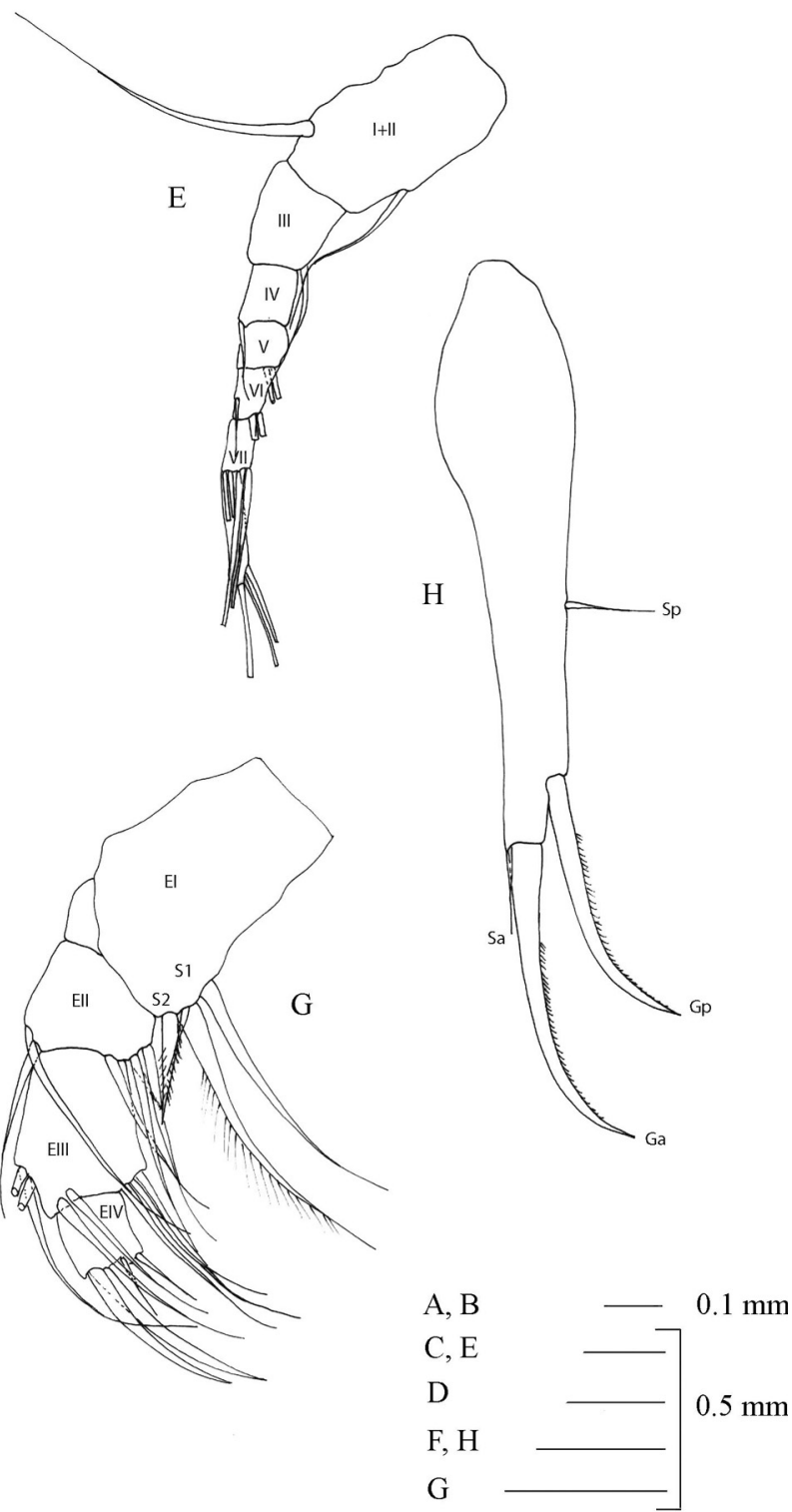

Fig. 10. Cryptocandona racovitzai sp. nov. (female form Şuncuiuş): A - left valve in outer view, B - right valve in outer view, C - L6, D - L7, E - first antenna, F-A2, G - mandibular palp, H - CR. 
$0.5 \times$ its length (Table 4, Fig. 10F). Length of the terminal claw of the walking leg $\left(\mathrm{h}_{2} \mathrm{~L} 6\right)$ variable and equalling 2.1-3.3× L6EII (Fig. 10 C). Cleaning leg 4-segmented, endopodial podomeres EII and EIII fused; penultimate podomere with rows of setulae on the postero-distal end, just above the distal seta $\mathrm{g}$, the shortest apical seta $\left(\mathrm{h}_{1}\right)$ hook-like and recurved downwards (Fig. 10D). Relative lengths of the three apical setae as follows: $\mathrm{h}_{1}=$ $0.14-0.23 \times, \mathrm{h}_{2}=0.44-0.70 \times$ and $_{3}=1.34-1.84 \times$ of L 7EI (Table 5). Caudal ramus almost straight (Fig. 10H). Relative length of the claws, setae and distance between insertion points of $s_{p}$ and $G_{p}$ compared with CRAM as follows: $\mathrm{s}_{\mathrm{a}}=0.12-0.18, \mathrm{G}_{\mathrm{a}}=0.49-0.62, \mathrm{G}_{\mathrm{p}}=0.40-0.50$, $\mathrm{s}_{\mathrm{p}}=0.10-0.17, \mathrm{~s}_{\mathrm{p}}-\mathrm{G}_{\mathrm{p}}=0.21-0.35$ (Table 5). Female genital lobe evenly rounded and inconspicuously protruded.

\section{Males unknown}

Distribution and ecology. The new species is considered here a stygobite as it has so far been recorded from the groundwater of the Crişul Repede and Sighiştel Valley rivers in NW Romania at three sites (Fig. 1): the type locality (the village Şuncuiuş) and the villages of Bulz and Sighiştel (see Material and Methods).

\section{Discussion}

Since from the populations we dealt with here only females and juveniles were collected, we assume that at these sites ostracods reproduce parthenogenetically. This was unfortunate as the male genital morphology in the genus Cryptocandona offers better characteristics than that of the female on which to define taxonomic position of the species (Namiotko et al. 2005b). Although it is clear that the studied all-female populations form separate entities, potentially reproductively isolated, we faced the classical nomenclatorial problems with the taxonomy of parthenogens. However, with the obtained information from our morphological study, we were able to develop ideas of how to approach the studied populations from a taxonomic and evolutionary standpoint.

The quantitative data on the morphological disparity of the valves, as expressed by the values of the MPD index and its confidence limits, show varied degrees of variability. The AL and SU populations display lower variability as compared to those of the $\mathrm{AR}$ and $\mathrm{BU}$ ones (Table 2 and the N-MDS plot in Fig. 8A). These differences could be explained by the way in which the parthenogenetic populations originated at these sites. The founder effect and the number of colonisations of these subsurface habitats can explain the differences in the range of morphological disparity described above. A par- thenogenetic population can be established just by one or a few individuals displaying a unique phenotype and carrying only a small fraction of the original population's genetic variation or by many individuals with a wider spectrum of phenotypes and being more heterogeneous genetically. As a result, the new population may be distinctively different, both genetically and phenotypically, from the source population from which it has been derived. Repeated colonisation of one site can also during time increase the morphological disparity of such groundwater dwelling ostracod populations. A much similar situation was mentioned by Iepure et al. (2007) for the parthenogenetic populations of $P$ seudocandona eremita (Vejdovský, sensu lato) found in closely located wells from the same village Gilău in Cluj county (Romania).

In the previous contributions on Cryptocandona vavrai lineage Baltanás et al. (2000) and Namiotko et al. (2005b) stressed out the polymorphism of both the valve shapes and the limbs. Considering the valves, the former authors noticed that the morphological differences of the shape are, as compared to other Candoninae groups, much attenuated (slight "variations on a theme"), reflecting the solution of the "catenary arch model" favoured by Benson (1975). In the opinion of Baltanás et al. (2000) the slight variations of the carapace shape among the various populations of $C$. vavrai cannot be explained as a product of the adaptive process to the habitats where these populations were found. The present study brings additional arguments for this view because we do not see any morphological changes in the carapace shape related either to the habitat type or to the geographic location of these populations. The micro-evolutionary aspects of the valve shape are expressed through slight differences in both the dorsal and the ventral parts of the outline as well as the development of the inner lamella. The same applies to the slight morphological differences in the limb traits described above (Table 4 and 5, Fig. 9). Hence, we hypothesise that the described micro-evolutionary changes, beside the mentioned founder and repeated colonisation effects, may also be caused by selectively neutral changes, organismically cued. The multivariate analyses, like the N-MDS (Fig. 8) and especially the ANOSIM (Table 3), point out strong separation of the Alas valves and those from Şuncuiuş-Bulz, i.e. separation between populations located in geographically remote areas, the Pyrenean and the Carpathian mountain chains, respectively (Fig. 1). Furthermore, the valve shape of the population from Isverna, the site situated in southern Carpathians (Fig. 1), shows that even in an area closer to that were $C$. racovitzai $\mathrm{sp}$. nov. occurs, populations with relatively distinct morphology exist. The IS population, if diagnosable, may possibly represent another new species but this needs further investigations. 
The criteria we use here for the delineation of the western Romanian populations as a new species $C$. racovitzai sp. nov. started from the idea that a species should be identified clearly on morphological traits that one can find on any adult individual of a given sex. Within a polymorphic phylogenetic lineage like the Cryptocandona vavrai (sensu lato) species should be defined by gaps within the morphologic variation of a trait (Wiley 1981, Balakrishnan 2005, K. Martens oral communication to D.L.D.). Although the clear separation of the investigated populations was statistically illustrated, we avoided the definition of taxa based solely on morphological traits identified with statistical methods, like the 75\% subspecies criterion favoured by Simpson (1961), or on the multidimensional system of Sbordoni (1993) in which a species is defined as a group of individuals discretely separated from others in the morphological space. Therefore, the new species $C$.racovitzai sp. nov. is defined here through several quantitative continuous variables or ratios.

Furthermore, one could argue that as compared with the original description of $C$. vavrai by Kaufmann (1900b) the ventral part of the valves of the Alas and Arcine populations could give enough information in order to separate them into additional new taxa. We did not decided on this issue as far we will not examine additional Swiss material from sites closely located to the type locality, and moreover, we are not sure that the concave ventral margin figured by Kaufmann (1900b) is a correct description. Most of the examined specimens from various European localities display a straight or slightly incurved ventral margin of the valve (Baltanás et al 2000, Namiotko et al. 2005b).

A brief comparison between C. racovitzai sp. nov. and C. vavrai is further given, in order to better illustrate the morphological characteristic of the new described species. Females of $C$. racovitzai sp. nov. are on average slightly larger $(\geq 0.95 \mathrm{~mm}$, usually $>1.00 \mathrm{~mm})$ than those of $C$. vavrai $(0.77-0.93 \mathrm{~mm}$, see Table 1 and Meisch 2000). Valves of the new species are elongated and dorsally weakly arched in side view, with the postero-dorsal part relatively weakly elevated (the ratio of the posterior height at $85 \%$ of the maximum valve length to the maximum valve height HP85\% / HM always inferior to 80, Table 1), whilst those of $C$. vavrai display more rectangular shape, with the posterior third generally better developed than the anterior one and broadly rounded, as seen in the topotype specimen from Gentilino in Fig. 2B (HP85\%/HM > 80, cf. Table 1). The greatest valve height in $C$. racovitzai sp. nov. is situated behind mid-length at $51-56 \%$ of the maximum valve length versus at $47-51 \%$ in $C$. vavrai. The inner lamella of $C$. racovitzai sp. nov. is less developed than that of $C$. vavrai (see $\mathrm{La} 20^{\circ} / \mathrm{LM}$ index in Table 1). The major differences in the appendages refer to the relative length of the antennal claw $\mathrm{G}_{2}$ that is slightly shorter in $C$. racovitzai sp. nov. $\left(\right.$ ratio $\mathrm{G}_{2} /$ A2EI ranges 0.59-0.73) than that in $C$. vavrai (this ratio 0.73-0.82, Table 4). Finally, C. racovitzai sp. nov. differs from $C$. vavrai in the relative length of the posterior claw of the caudal ramus, which is also shorter in the new species (ratio $\mathrm{G}_{\mathrm{p}} / \mathrm{CRAM}=0.40-0.50$ ) than that of $C$. vavrai (this ratio $0.50-0.58$, cf. Table 5).

As a final point, one could address questions on the origin and the antiquity of $C$. racovitzai sp. nov. We assume two alternative scenarios: (1) The new species belongs to an old group of the Cryptocandona lineage, more diverse during past geologic time (e.g. as it could occur during the Tertiary), as compared to the present day fauna; (2) The new species diverged from the widely spread species C. vavrai and that could happen any time, even in the near past. To corroborate or to falsify one of these scenarios it would be useful to continue to describe other populations of $C$. vavrai using also molecular criteria in order to further detect microevolutionary changes and to reconstruct phylogenetic affinities of these populations with living and fossil candonids. We know that species of the lineage C. vavrai already existed in the Upper Miocene swampy habitats, at the periphery of the Lake Panon in Central Europe (R. Pipik and D. L. Danielopol, MS in preparation). The latter aspects are being dealt with in an ongoing research project "Diversity of Recent subterranean and Paratethyan ostracods", lead by D.L.D.

\section{Acknowledgements}

S.I. and T.N. benefited from the scientific exchange programmes between the Austrian Academy of Sciences, and its Romanian and Polish homologues for the repeated financial support for travel and work facilities at the Institute of Limnology in Mondsee. D.L.D. acknowledges the financial support of the Austrian Science Fund (Grant FWF P17738-B03). This investigation benefited also from the EU Marie Curie Research Training Network (Contract no. MRTN-CT-2004-512492). I. Tabacaru, D. Dancau and E. Şerban (Bucharest) helped D.L.D. during 1967 to sample several Romanian populations of ostracods studied here. The material from Arcine was offered by P. Marmonier (Lyon) and that from Alas by R. Rouch (at that time in Moulis). O.T. Moldovan (Cluj) and J. Notenboom (Bilthoven) helped S.I. during her sampling programme at Bulz. R. Pipik (Banská Bystrica) is acknowledged for showing us valves of a new fossil species of the Cryptocandona vavrai lineage from Upper Miocene of Slovakia. J. Knoblechner (Mondsee) helped with the morphometric analysis of the material used in the present study. The advice and intensive discussions on morphometrics with A. Baltanás (Madrid), W. Neubauer and J. Linhart (both Salzburg) as well as discussions with K. Martens (Brussels) on the way one can delineate morphologically species as taxonomically recognisable units are much appreciated. Finally, we thank R. Cereghino (Toulouse) and Cl. Meisch (Luxembourg) for critical reading of an earlier version of the manuscript. 


\section{References}

Baltanás A., Namiotko T. \& Danielopol D. L. 2000. - Biogeography and disparity within the genus Cryptocandona (Crustacea, Ostracoda). Vie Milieu, 50, 297-310.

Baltanás A., Brauneis W., Danielopol D.L. \&. Linhart J. 2003. Morphometric methods for applied ostracodology: Tools for outline analysis of nonmarine ostracods. Paleont. Soc. Papers, 9, 101-118.

Balakrishnan R. 2005. - Species concepts, species boundaries and species identification: A view from the tropics, Syst. Biol., 54, 689-693.

Benson R.H. 1975. - Morphologic stability in Ostracoda. Bull. Amer. Paleont., 65, 13-46.

Brauneis W., Linhart J., Stracke A., Danielopol D.L., Neubauer W. \& Baltanás A. 2006. - Morphomatica Version 1.6.0 Software \& User Manual/Tutorial. Commission for the Palaeontological and Stratigraphical Research of Austria, Austrian Academy of Sciences, c/o Institute of Earth Sciences (Geology \& Palaeontology) University of Graz, http://palstrat.uni-graz.at/ morphomatica/morphomatica_e.htm.

Broodbakker N.W. \& Danielopol D.L. 1982. - The chaetotaxy of Cypridacea (Crustacea, Ostracoda) limbs: proposal for a descriptive model. Bijdr. Dierk., 52, 103-120.

Ciampaglio C.N., Kemp M. \& McShea D.W. 2001. - Detecting changes in morphospace occupation pattern in the fossil record: characterisation and analysis of measure of disparity. Paleobiology, 27, 695-715.

Clarke K.R. \& Gorley R.N. 2006. - Primer v. 6: Computer program and User Manual/Tutorial. PRIMER-E Ltd., Plymouth Marine Laboratory, Plymouth, $192 \mathrm{p}$.

Clarke K.R. \& Warwick R.M. 2001. - Change in marine communities: An approach to statistical analysis and interpretation. Plymouth Marine Laboratory, Plymouth, $172 \mathrm{p}$.

Danielopol D.L. 1980. - An essay to assess the age of the freshwater interstitial ostracods of Europe. Bijdr. Dierk., 50, 243-291.

Iepure S. 2007. - Aspecte micro-evolutive la specii de ostracode (Crustacea, Ostracoda) si ciclopide (Crustacea, Copepoda) din ape subterane. Doctoral Thesis, Academia Română, Institutul de Speologie "Emil Racoviță", Bucharest, 159 p. (in Romanian).

Iepure S., Namiotko T. \& Danielopol D.L. 2007. - Evolutionary aspects within the species group Pseudocandona eremita (Vejdovský) (Ostracoda, Candoninae). Hydrobiologia, 585, 159-180.

Kaufmann A. 1900a. - Neue Ostracoden aus der Schweiz. Zool. Anz., 23, 131-133.

Kaufmann A. 1900b. - Cypriden und Darwinuliden aus der Schweiz. Rev. Suisse Zool., 8, 209-423.

Krebs C.J. 1999. - Ecological methodology. Addison-Wesley Educational Publ., Inc. Menlo Park, Ca, 620 p.

Mallard F., Reygrobellet J.L., Laurent R. \& Mathieu J. 1997. Developments in sampling the fauna of deep water-table aquifers. Arch. Hydrobiol., 138, 401-432.
Manly B.F.J. 1998. - Multivariate statistical methods. A primer. Chapman \& Hall, London, 215 p.

Meisch C. 2000. - Freshwater Ostracoda of Western and Central Europe. Spektrum Akad. Verlg., Heidelberg, Berlin, 522 p.

Namiotko T. \& Danielopol D.L. 2001. - Redescription of two rare hypogean species of the genus Cryptocandona Kaufmann (Ostracoda). Crustaceana, 74, 557-580.

Namiotko T. \& Danielopol D.L. 2002. - Morphology and phylogenetic affinities of Cryptocandona brehmi (Klie, 1934) (Ostracoda, Podocopida). Crustaceana, 74, 1349-1363.

Namiotko T., Marmonier P. \& Danielopol D.L. 2005a. Cryptocandona kieferi (Crustacea, Ostracoda): redescription, morphological variability, geographical distribution. Vie Milieu, 55, 91-108.

Namiotko T., Marmonier P., Danielopol D.L., Horne D.J. \& Artheau M. 2005b. - New records of rare males of Cryptocandona vavrai Kaufmann 1900 (Crustacea, Ostracoda), with further additions to the description of the species. Ann. Limnol., 41, 203-219.

Namiotko T., Meisch C., Gidó Z. \& Danielopol D.L. 2001. Redescription, taxonomy, distribution and ecology of Cryptocandona dudichi (Klie, 1930) (Crustacea, Ostracoda) Bull. Soc. Nat. luxemb., 102, 109-130.

Neubauer W. 2007. - Measuring the difference of approximating B-spline curves with application in distinguishing Ostracoda. MSc Thesis, Institute of Mathematics, Univ. Of Salzburg, 85 p. Commission for the Palaeontological and Stratigraphical Research of Austria, Austrian Academy of Sciences, c/o Institute of Earth Sciences (Geology \& Palaeontology) University of Graz, http://palstrat.uni-graz.at/morphomatica/morphomatica_e.htm.

Rogulj B., Danielopol D.L., Marmonier P. \& Pospisil P. 1993. Adaptive morphology, biogeographical distribution and ecology of the species group Mixtacandona hvarensis (Ostracoda, Candoninae). Mém. Biospéol., 20, 195-207.

Rohlf F.J. 2003. - Tps-dig, Program, Version 1.37. Department of Ecology and Evolution, State University of New York, Stony Brook, NY, http//Life.Bio.SUNYSB.edu/morph/morph/html.

Rouch R. 1988. - Sur la repartition des Crustacés dans le sous-écoulement d'un ruisseau des Pyrénées. Ann Limnol., 24, 213-234.

Sbordoni V. 1993. - Molecular systematics and the multidimensional concept of species. Biochem. Syst. Ecol., 21, $39-42$.

Simpson G.G. 1961. - Principles of animal taxonomy. Columbia Univ. Press, New York, $247 \mathrm{p}$.

StatSoft, Inc. 2007. - Electronic Statistics Textbook. StatSoft, Tulsa OK. WEB: http://www.statsoft.com/textbook/stathome.html.

Wiley E.O. 1981. - Phylogenetics, the theory and practice of phylogenetic systematics. J. Wiley \& Sons, New York, 456 p.

Winther R.G. 2001. - Varieties of modules, kinds, levels, origins and behaviours. J. exp. Zool., 291, 116-129. 